\title{
Capítulo 12 - Ciência feminista, história e epistemologia
}

\author{
Clara Guimarães \\ Graciela de Souza Oliver
}

\section{SciELO Books / SciELO Livros / SciELO Libros}

GUIMARÃES, C., and OLIVER, G.S. Ciência feminista, história e epistemologia. In: MOURA, B. A., and FORATO, T. C. M., comps. Histórias das ciências, epistemologia, gênero e arte: ensaios para a formação de professores [online]. São Bernardo do Campo, SP: Editora UFABC, 2017, pp. 237-253. ISBN 978-85-68576-84-7. https://doi.org/10.7476/9788568576847.0013.

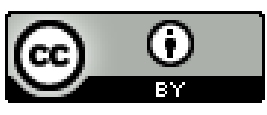

All the contents of this work, except where otherwise noted, is licensed under a Creative Commons Attribution 4.0 International license.

Todo o conteúdo deste trabalho, exceto quando houver ressalva, é publicado sob a licença Creative Commons Atribição 4.0.

Todo el contenido de esta obra, excepto donde se indique lo contrario, está bajo licencia de la licencia $\underline{\text { Creative }}$ Commons Reconocimento 4.0. 


\section{CIÊNCIA FEMINISTA, HISTÓRIA E EPISTEMOLOGIA}

Clara Guimarães Graciela de Souza Oliver

\section{Mulher e ciência}

Desde os primórdios do fazer científico o discurso era feito, basicamente, por homens. Os articuladores da ciência, tal como a conhecemos hoje, possuíam um discurso voltado para os pares masculinos. Como exemplo, podemos citar os trabalhos de Francis Bacon e Renée Descartes (HARDING, 1996; JAPIASSÚ, 2001). Nesse sentido, uma epistemologia feminista foi surgindo a partir de discussões sobre a participação das mulheres na ciência e na sociedade. Esses estudos acabaram questionando o estatuto de saber "solidificado" da ciência moderna.

Segundo Joana Maria Pedro e Miriam Grossi (1998), os estudos feministas buscam salientar o que a epistemologia tradicional tem ignorado: as relações de gênero como fator constituinte da ciência. Esses estudos também teriam admitido que a construção da identidade feminina é cultural e que se relaciona com a história das mulheres. A forma de pensar feminista trouxe 
à baila a subjetividade, contrariando a trajetória tradicional de organização do conhecimento utilizada pelas ciências humanas, advinda das ciências naturais. Sendo assim, o feminismo proporia novas relações entre teoria e prática, um cientista não mais isento, mas que constrói seu conhecimento por meio da interação com indivíduos.

Para Cecília Maria Bacellar Sardenberg e Ana Alice Alcântara Costa (2002, p. 12),

A perspectiva de gênero tem possibilitado a construção de uma epistemologia crítica feminista, um discurso feminista sobre a ciência e uma teoria crítica do conhecimento que, se por um lado fundamenta as bases de um saber feminista, por outro, vem abrindo espaço para questionamentos e reavaliações até mesmo dos próprios fundamentos desse saber.

Nessa perspectiva, a crítica feminista da ciência observa a discriminação das mulheres na estrutura social da ciência e o androcentrismo das ciências. Assim, uma de suas principais críticas está no objetivo totalizante do discurso científico, pois, apesar de se propor como neutra, a ciência não é neutra perante as questões de classe, de raça e de gênero. O resultado seria uma "ciência malconduzida", "distorcida pela visão masculina" (HARDING, 1993, p. 69). Uma ciência que até produz conhecimento sobre as mulheres, mas que não as leva em consideração como sujeitos ativos nas práticas científicas. Dessa forma, os estudos feministas passaram a propor uma nova perspectiva para o contexto científico, problematizando a invisibilidade das mulheres.

Nesse campo, podemos citar os estudos de história das ciências e gênero, que trouxeram à baila o fazer científico praticado por mulheres ao longo da história das ciências no Brasil. 
Muitas dessas mulheres realizaram importantes feitos não só no campo científico, mas também atuando diretamente na esfera política e social, contribuindo para o constante processo de emancipação feminina.

\section{História das ciências e os Estudos de gênero}

Os estudos feministas transitam por várias áreas do saber científico e, para isso, fazem uso da crítica feminista das ciências, apresentando novos modelos e propostas para pensar a ciência. Entretanto, os estudos mais específicos que relacionam história das ciências e gênero foram negligenciados, pois pouco se perguntou sobre essas mulheres que desbravaram as ciências ou mesmo como se deu a divulgação científica para o público feminino (LOPES, 2006b; LOPES; SOUZA, 2007; COSTA, 2006).

Um dos problemas dos historiadores das ciências é que não olham para a sociedade de forma geral, como apontam Lynn Nyhart e Thomas Broman (2002), dispensando as interações sociais. Neste sentido, a temática histórica, que vincula ciências e gênero, pode então contribuir para um novo olhar sobre as relações sociais, em que se compreenda o lugar que se destina ao público e ao privado num dado contexto.

Sendo assim, Maria Margaret Lopes (1998) e Lopes, Souza e Sombrio (2004) afirmam que Evelyn Fox-Keller ${ }^{1}$, em 1978, foi a primeira a relacionar e usar os termos gênero e ciências em conjunto. Isso demonstra quão recente (LOPES, 2008) é o campo história das ciências/do gênero. Entretanto, se pensarmos que a

\footnotetext{
${ }^{1}$ Ver, também, Qual foi o impacto do feminismo na ciência?, artigo publicado em Cadernos Pagu (FOX-KELLER, 2006).
} 
história das ciências existe como disciplina desde o século XIX, podemos entender historicamente a invisibilidade das mulheres, uma vez que a ciência se torna defensora da superioridade cultural da civilização ocidental. Já as mulheres, a partir desse mesmo período, seriam cada vez mais identificadas e simbolizadas pela maternidade e pela natureza não ordenada.

Entretanto, é válido ressaltar que sua vertente social e cultural surgiu apenas depois da década de 1980 (LOPES, 2006b). Por essa razão, para que os estudos de gênero e ciência se expandam, é necessário que se transcenda a visão de que a única possibilidade de existência de um fazer científico nos séculos passados no Brasil fosse masculina, dado que o acesso das mulheres às universidades, no Brasil, deu-se apenas em 1879.

Assim, o movimento historiográfico deveria ser de "recuperar, avançar e criar novas tradições, que nos permitam tornar visíveis as mulheres e as relações de gênero em nossos fazeres científicos" (LOPES, 1998, p. 366).

Além disso, Foucault (2007) menciona que a história não é feita só do que está escrito, mas também do que está implícito e dos silenciamentos. Caberia, então, pesquisar em outros tipos de espaços públicos ou privados para o período anterior a 1879. Dessa forma, os estudos de gênero e história das ciências trazem à baila um novo campo de investigação, que lida com a construção e a naturalização "das diferenças de sexo e gênero". Para Löwy (2000, p.22/23), a solução "[...] de continuidade entre o social, o cultural e o político na construção da natureza feminina ou masculina tornou-se uma das preocupações principais dos historiadores/as das ciências interessados/as nas questões de gênero".

Outros marcos foram surgindo, no decorrer do tempo, postergando a entrada das mulheres como sujeitos históricos na produção da ciência moderna. A literatura científica demonstra 
que as pesquisas apontam, entre outras coisas, para um aumento significativo das mulheres no ensino superior no Brasil a partir de 1970 (AZEVEDO; FERREIRA, 2006; AZEVEDO et al., 2004; MELO; RODRIGUES, 2006; GUEDES, 2008) e que representam a maioria nos cursos universitários (COSTA, 2006). Os dados mostram também que as mulheres passam mais tempo estudando do que os homens, e a hipótese levantada por Moema de Castro Guedes (2008) é que isso ocorre devido às escassas oportunidades de trabalho. Entretanto, Osada e Costa (2007) apontam que, apesar de os níveis de escolaridade das mulheres serem iguais ou até maiores, encontramos mais homens do que mulheres em cargos de chefia, pois a equiparidade quantitativa não significa igualdade de condições sociais entre os gêneros (AZEVEDO; FERREIRA, 2006; AZEVEDO et al., 2004; GUEDES, 2008; FERREIRA et al., 2008).

Outro problema enfrentado pelas mulheres pesquisadoras seria a falta de práticas que incentivem questões femininas, como no caso da maternidade, pois não existem políticas específicas de apoio, chegando a casos de cortes de bolsa em períodos de afastamento por maternidade (OSADA; COSTA, 2007).

Entretanto, questões como maternidade e casamento devem ser observadas de uma forma mais ampla e complexa, e não entendidas como os únicos fatores determinantes para que as mulheres não ocupem tantos cargos de chefia, publiquem menos, publiquem textos com mais colaboradores ou até abandonem a carreira de pesquisadoras (FERREIRA et al., 2008).

Assim, um dos mais importantes incentivos às mulheres na produção científica são bolsas, prêmios, apoios às pesquisas e intercâmbios, estimulando a manutenção da mulher no campo científico. A criação do CNPq em 1951 (FERREIRA et al., 2008; LOPES; SOUZA; SOMBRIO, 2004; AZEVEDO et al., 2004; 
AZEVEDO, CORTES E SÁ, 2008), por exemplo, é um marco nesse aspecto, pois a entidade custeou pesquisas de várias cientistas, tais como: Bertha Lutz (SOUZA; SOMBRIO; LOPES 2005; ANGÓS, 2008), Leda Dau e Aída Vassón-Voloch. Sobre essas mudanças, podemos afirmar que:

[...] ensejaram o aparecimento de condições institucionais que permitiram tornar a ciência uma opção para um contingente expressivo de mulheres que, valendo-se das estratégias e dos modelos profissionais então disponíveis, contribuíram para a redefinição das balizas que demarcavam as relações de gênero no Brasil. (AZEVEDO; CORTES; FERREIRA, 2008).

Pudemos observar que as mulheres que integraram os quadros de pesquisas do Brasil até os anos 1970 tiveram dois fatores fundamentais que as auxiliaram na escolha e permanência na profissão: o apoio da família e uma situação financeira mais estável (MELO; RODRIGUES, 2006; AZEVEDO et al., 2004; AZEVEDO; CORTES; FERREIRA, 2008; OLIVER; FIGUEIRÔA, 2007). A química Aída Vassón-Voloch (AZEVEDO et al., 2004), por exemplo, contou com o incentivo de seu pai para que estudasse, pois este deu suporte financeiro para que Aída ingressasse no curso e iniciasse a carreira.

Já a botânica Leda Dau comenta da importância do incentivo de seu irmão para que ingressasse na carreira de cientista (AZEVEDO et al., 2008). Com base nesses dados, podemos afirmar que, para que essas mulheres tivessem acesso à educação e à carreira de cientistas, precisaram do que chamamos de rede de apoio, que pode vir da família e/ou das agências de fomento. E, no campo educacional, entendemos que, para essas e outras mulheres - que Melo e Rodrigues (2006) chamam 
de pioneiras da ciência no Brasil -, a reformulação da educação ocorrida a partir dos anos 1920 e 1930 foi fundamental para o seu ingresso no ensino superior (FERREIRA et al., 2008).

Os anos 1920 são apontados como o contexto no qual foram formuladas as ideias fundamentais e empreendidas as ações pioneiras que lançaram as bases institucionais da moderna organização escolar brasileira, consolidadas nos anos 1930 e 1940 do século XX (AZEVEDO; FERREIRA, 2006).

Já a reforma educacional promovida pelo Ministério da Educação em 1942, que culminou na criação da UFRJ, e a "reforma do ensino secundário" tiveram um papel importante na legitimação da relação entre classes sociais, raças e gênero. Entretanto, para as mulheres, coube o ensino doméstico e o ensino normal, pois estes podem ser relacionados com a família e a administração do lar (AZEVEDO et al., 2004). Nesse sentido, a urbanização e as relações de gênero se estabelecem na sociedade capitalista continuando o modelo de distribuição de papéis preestabelecidos, restringindo a participação das mulheres em profissões que são consideradas inadequadas para elas. Essa relação de adequabilidade das profissões está baseada na ideia de que as mulheres são mais aptas às artes e à literatura, e os homens às ciências, pois eles são mais pragmáticos nas relações (AZEVEDO et al., 2004; GUEDES, 2008).

Isabel Guérin (2005) chama essa relação de "altruísmo", cuja definição seria essa designação que se dá à mulher ao assumir o papel de cuidadora, pois, nas sociedades antigas, o ser mulher estava relacionado com um dom, por isso era comum que as mulheres se ocupassem de tudo que se relacionasse ao cuidado do outro.

A especialização das mulheres nas atividades de proximidade não pode ser interpretada a partir de um 
fator único. Ela resulta de uma pluralidade de fatores em que as aspirações pessoais e a preocupação com outrem se entrecruzam com pressões de diversos graus, desde o imperativo da sobrevivência até o simples respeito às normas sociais em vigor, passando pela interiorização de um senso do dever e da dedicação. (GUÉRIN, 2005, p. 38).

O termo "atividade de proximidade" foi cunhado por Nancy Folbre e significa o "envolvimento das mulheres no cuidar de outras pessoas". A entrada das mulheres no mercado de trabalho teria a potencialidade de reforçar a segregação profissional de gênero, pois as mulheres ocupariam em larga escala profissões que remetem ao cuidado com o outro (GUÉRIN, 2005, p. 39). Sendo assim, "[...] definitivamente, seja em sua família ou enquanto assalariadas, as mulheres são conduzidas, mais que os homens, a exercer um 'trabalho afetivo' que pressupõe 'competências de educadora e mediadora'” (GUÉRIN, 2005, p. 40).

As mulheres são mais encontradas em profissões de cuidado, tais como professora, babá, secretária, enfermeira, empregada doméstica. $\mathrm{E}$, na maioria dos casos, as mulheres são mais vistas em atividades não remuneradas do que os homens, mas isso seria uma questão de gênero, pois esse "altruísmo" feminino estaria ligado a um mecanismo de exploração e dominação das mulheres, que tornaria a mulher alienada, alheia e "despossuída de seu corpo ou de sua força de trabalho" (GUÉRIN, 2005, p. 41). As mulheres sempre trabalharam, já que cuidavam de seus lares e faziam esses trabalhos não remunerados, o que muda nesse sentido é o contexto da industrialização e urbanização, levando as mulheres para o trabalho fora de casa, mas mantendo-as nessas profissões de cuidados, como se fosse a sua única vocação trabaIhar com o cuidado dos outros e das coisas. 
Oliver (2009, p. 233) discorre sobre a educação das muIheres da classe alta, que visava suprir as necessidades do lar e da criação dos filhos dentro dos padrões adequados de conduta, e sempre concentrada na manutenção da saúde das crianças. Desde o final do século XIX, as mulheres passaram a frequentar espaços públicos e a obter uma escolaridade que desse suporte às "obrigações femininas", pois a mulher teria o cuidado do lar como vocação. Apesar dessa relação entre mulher e lar, a autora se debruça sobre os locais e papéis que essas mulheres perfazem no contexto do fazer científico. Questiona-se sobre onde estão as mulheres no campo científico, principalmente na agronomia, e qual o perfil das esposas dos cientistas (OLIVER, 2009).

Oliver (2009, p. 230) cita o livro Psicología General², publicado em 1927, que discute também quais as características das esposas desses cientistas e traz a seguinte afirmação: "Os autores argumentam que as esposas ideais deveriam ter como características a iniciativa própria e a capacidade de cuidar do lar e da família sozinhas". Essa mulher deveria ter como característica principal dar total suporte ao marido, poupando-o de situações que possam promover desgastes físicos ou mentais que atrapalhem a sua pesquisa, e também basear todas as suas ações em informações obtidas por meio da divulgação científica.

Londa Schiebinger (2008, p. 274) chama essa relação hierárquica obtida pelo casamento de hipergamia, pois afirma que as mulheres têm a tendência de casar-se com homens de status superior ao delas, pois o reconhecimento social feminino se dá pelo casamento. Nesse sentido, afirma que, hoje em dia,

2 SANCHEZ, José Rogério; EGIDIO, Vicente Feliu. Psicología General, Madrid: Hernando, 1927. 
as mulheres ${ }^{3}$ cientistas tendem a casar com homens também cientistas, e que uma parcela considerável se relaciona com parceiros da mesma área acadêmica.

A pesquisa de Oliver (2009, p. 231) trata do ensino de agronomia no Brasil e, entre os diversos elementos trazidos neste contexto, discutiu, também, a inserção da mulher nas escolas de agronomia de nível superior entre os anos de 1930 e 1950. Em análise de 2.082 registros desse período, Oliver encontra somente 21 mulheres matriculadas, concluindo que se podem encontrar mais mulheres nos cursos de "arquitetura e de engenharia química" do que nos de agronomia. Neste contexto de profissão, predominantemente masculino, o primeiro elemento feminino antes de 1930 é a imagem de Ceres nos quadros de formatura, bem como as referências escritas à própria escola como uma figura feminina. (OLIVER, 2009, p. 231).

Graciela de Souza Oliver e Sílvia Fernanda de Mendonça Figuerôa (2007, p. 379) realizam uma análise dessas imagens de Ceres, que é uma figura emblemática nos quadros de formatura da época. Em um primeiro momento, fazem referência a Londa Schiebinger e relatam que Ceres é representada "sempre no plano inferior dos quadros", legitimando, assim, sua posição de musa. A imagem de Ceres foi interpretada de duas maneiras: "como a mulher que semeia ou como a mulher guardiã".

Logo, as duas interpretações coadunam o entendimento que se tem do "papel social da época", ou seja, Ceres faz a ligação entre a escola agrícola e o lar, mas também sua imagem demonstra que podemos entender que existe uma vocação científica que faz sentido ao agrônomo, um local específico para ela. Na esfera do discurso textual, a Casa de Ceres, como

${ }^{3}$ A autora se refere a mulheres heterossexuais e Cis em sua pesquisa. 
lugar feminino, sacraliza o Templo da Ciência, onde se aprendem os primeiros passos no domínio da natureza e da agricultura (OLIVER; FIGUEIRÔA, 2007, p. 380-381).

Nas relações entre o campo, as ciências e suas relações com a agronomia, coube às mulheres o papel coadjuvante; sendo assim, somente nove daquelas 21 engenheiras agrônomas formadas se voltaram para o campo do experimento. Entretanto, apesar de terem sido uma minoria na área, essas mulheres representaram novas possibilidades de profissionalização para outras mulheres, que puderam ingressar na carreira (OLIVER; FIGUEIRÔA, 2007, p. 392-393). E é por isso que estudar história das ciências e gênero é tão importante para a visibilidade feminina, pois "[...] essas 'invisíveis' mulheres construíram suas carreiras no passado e continuam a construí-las, mesmo em áreas ainda consideradas masculinas como a Informática" (LOPES; SOUZA, 2007). Mas, além disso, consideramos importante entender quais relações podem ter surgido entre as ciências e as mulheres, quais discursos e contextos podem ter afastado as mulheres das diferentes práticas científicas e transformado essas práticas, no cotidiano praticado pelo senso comum, em um lugar da ação masculina.

\section{Considerações finais}

Ao relacionarmos mulher e ciência, a primeira coisa que podemos apontar é o aparente distanciamento entre ambas. Esse processo - ou tentativa - de afastamento se dá desde os primeiros momentos de socialização, quando as mulheres são direcionadas às atividades marcadas como "femininas". Essas "características" também são utilizadas para justificar e incentivar as mulheres a 
se aproximarem das ciências humanas e se afastarem das ciências naturais (COSTA, 2006).

A objetividade, a universalidade, a neutralidade científica e o determinismo tecnológico são algumas das características da ciência mais criticadas pela epistemologia feminista. Mas, segundo Lopes (2006a), as imagens dos ideais de "masculinidade da cultura moderna europeia" também podem ser entendidas como uma causa reconhecida para a "invisibilidade das mulheres em ciências", e quem sabe até mais do que a objetividade como fator principal da exclusão feminina.

Ao analisar casos específicos, como os breves exemplos abordados aqui, conclui-se que, a cada tempo e contexto, a invisibilidade permaneceu paralelamente ao relativo aumento de brechas e oportunidades sociais e no campo científico.

Por essa razão, Hilton Japiassú (2001, p. 67-83) afirma que "[...] a ciência moderna é portadora de uma dimensão tipicamente machista [...]", pois seria um universo de controle produtivo e que possuiria um código masculino, assim, essa linguagem científica seria baseada num universo "patriarcal, masculino e machista".

A ciência, então, buscaria elaborar conceitos que dominariam a natureza, dando o controle aos homens, e esse movimento seria normatizante, já que "[...] pela ciência que o homem tem acesso à realidade [...]. Porque se apresenta como o melhor conhecimento"; por isso, surge a necessidade de abordar todas as situações "cientificamente" (JAPIASSÚ, 2001, p. 73), ordenando a esfera pública do conhecimento. Podemos entender que o uso da linguagem científica nas esferas públicas propiciaria também a produção e reprodução da modernidade e de suas características de gênero. 
Além do discurso científico normatizante - que é amplamente divulgado e baseado na necessidade do "comprovado cientificamente", reproduz-se a dicotomia da ciência, que se baseia, antes de tudo, na relação masculino e feminino, que é a mesma do racional/irracional, da objetividade/sensibilidade, do público/privado. Essa dualidade somente reforça as relações de gênero no discurso e no fazer científico, podendo sinalizar, em diversos contextos, que esse fazer não era, ou é, para as mulheres.

Entretanto, como mostramos ao longo do texto, a história das ciências e gênero é também um campo científico que problematiza o trabalho de pesquisa feminina nas ciências, desconstruindo o discurso binário que diferencia características masculinas e femininas e que direciona a mulher ao privado, profissões de cuidado, afirmando a existência de uma incapacidade feminina de lidar com questões lógicas e práticas. Dessa forma, o lugar das mulheres - cujas práticas científicas, desenvolvidas ao longo da história, foram muito importantes - também é nas ciências.

\section{Referências}

ANGÓs, Teresa Nuño. Consideraciones sobre género y ciencias en la trayectoria feminista de Bertha Maria Júlia Lutz (18941976). In: MIQUEO, Consuelo Miqueo et al. (Coord.). Estudios iberoamericanos de género en ciencia, tecnología y salud. Espanha: Prensa Universitária de Zaragoza, 2008. p. 509-514

AZEVEDO, Nara; CORTES, Bianca Antunes; FERREIRA, Luiz Otávio; SÁ, Magali Romero. Gênero e ciência: a carreira científica de Aída Hassón-Voloch. Cadernos Pagu, Campinas, v. 23, p. 355387, jul./dez. 2004. 
; ; .; Um caminho para a ciência: a trajetória da botânica Leda Dau. História, Ciência, Saúde - Manguinhos, Rio de Janeiro, v. 15 (suplemento), p. 209-229, jun. 2008.

.; FERREIRA, Luiz Otávio. Modernização, políticas públicas e sistemas de gênero no Brasil: educação e profissionalização feminina entre as décadas de 1920 e 1940. Cadernos Pagu, Campinas, v. 27, p. 217-220, jul./dez. 2006.

COSTA, Maria Conceição da. Ainda somos poucas: exclusão e invisibilidade na ciência. Cadernos Pagu, Campinas, v. 27, p. 455459, jul./dez. 2006.

FERREIRA, Luís Otávio; AZEVEDO, Nara; GUEDES, Moema; CORTES, Bianca. Institucionalização das ciências, sistema de gênero e produção científica no Brasil (1939-1969). História, Ciências, Saúde-Manguinhos, Rio de Janeiro, v. 15 (suplemento), p. 43-71, jun. 2008.

FOUCAULT, Michel. Microfísica do poder. São Paulo: Graal, 2007.

FOX-KELLER, Evelyn. Qual foi o impacto do feminismo na ciência? Cadernos Pagu, Campinas, v. 27, p. 13-34, jul./dez. 2006.

GUEDES, Moema de Castro. A presença feminina nos cursos universitários e nas pós-graduações: desconstruindo a ideia da universidade como espaço masculino. História, Ciência, Saúde - Manguinhos, Rio de Janeiro, v. 15 (suplemento), p. 117-132, 2008.

GUÉRIN, Isabel. As mulheres e a economia solidária. São Paulo: Edições Loyola, 2005.

HARDING, Sandra. A instabilidade das categorias analíticas na teoria feminista. Estudos Feministas, v. 1, n. 1, p. 7-31, jan./ jun.1993. 
. Ciencia y Feminismo. Madrid: Ediciones Morata, 1996.

JAPIASSÚ, Hilton. O projeto masculino-machista da ciência moderna. In: SOARES, Luiz Carlos (Org.). Da Revolução Científica à Big Science. São Paulo: Mussite/EDUFF, 2001. p. 67-104.

LOPES, Maria Margaret. O Brasil descobre a pesquisa científica: os museus e as ciências naturais no século XIX. São Paulo: Hucitec, 1997.

- "Aventureiras" nas Ciências: refletindo sobre Gênero e História das Ciências Naturais no Brasil. Cadernos Pagu, Campinas, v. 10, p. 345-368, 1998.

. Apresentação. Cadernos Pagu, Campinas, v. 27, p. 9-11, $2006 a$.

- Sobre as convenções em torno de argumentos de autoridade. Caderno Pagu, Campinas, v. 27, p. 35-61, $2006 \mathrm{~b}$.

. Apresentação ao artigo de Londa Schiebinger. História, Ciências, Saúde-Manguinhos, Rio de Janeiro, v. 15 (suplemento), p. 269-281, jun. 2008.

. SOUSA, Lia Gomes Pinto de. Mulheres nas ciências naturais: produção científica de Bertha Maria Júlia Lutz (18941976), a partir da década de 1940. In: SILVA, Cristiani Bareta da; ASSIS, Gláucia de Oliveira; KAMITA Rosana Cássia et al. (Org.). Gênero em movimento: novos olhares, muitos lugares. Florianópolis: Editora Mulheres, 2007. p. 59-74.

; ___ SOMBRIO, Mariana Moraes de Oliveira, A construção da invisibilidade das mulheres nas ciências: a exemplaridade de Bertha Maria Júlia Lutz (1894-1976), Gênero - NUTEG, v. 5, p. 97-109, 2004. 
LÖWY, Ilana. Universalidade da ciência e conhecimentos "situados". Cadernos Pagu, Campinas, v. 15, p. 15-38, 2000.

MELO, Hildete Pereira de; RODRIGUES, Ligia M. C. S. Pioneiras da ciência no Brasil. Rio de Janeiro: Sociedade Brasileira para o Progresso da Ciência, 2006.

NYHART, Lynn; BROMAN, Thomas. Science and Civil Society. Osiris 17. Chigaco: University of Chicago Press, 2002.

OLIVER, Graciela de Souza, Institucionalização das ciências agrícolas e seu ensino no Brasil, 1930-1950. São Paulo: Annablume, 2009.

.; FIGUEIRÔA, Silvia Fernanda de Mendonça. Ceres, as mulheres e o sertão: representações sobre o feminino e a agricultura brasileira na primeira metade do século XX. Cadernos Pagu, Campinas, v. 29, p. 365-397, jul./dez. 2007.

OSADA, Neide; COSTA, Conceição. A construção da Nova Biologia: relações de gênero nos laboratórios do Projeto Genoma da Fapesp. Cadernos de gênero e tecnologia, Curitiba, ano 3, n. 11, p. 21-34, 2007.

PEDRO, Joana; GROSSI, Miriam (Org.). Masculino, feminino, plural. Florianópolis: Ed. Mulheres, 1998.

SARDENBERG, Cecília Maria Bacellar; COSTA, Ana Alice Alcântara (Org.). Feminismo, Ciência e Tecnologia. Salvador: Rede Feminista Norte e Nordeste de Estudos e Pesquisa sobre Mulher e Relações de Gênero (REDOR), Núcleo de Estudos Interdisciplinares sobre a Mulher (NEIM), Universidade Federal da Bahia, 2002. v. 8. (Coleção Bahianas). 
SCHIEBINGER, Londa. Mais mulheres na ciência: questões de conhecimento. Apresentação de Maria Margaret Lopes. História, Ciências, Saúde - Manguinhos, Rio de Janeiro, v. 15 (suplemento), p. 269-281, 2008.

SOUZA, Lia Gomes Pinto de; SOMBRIO, Mariana Moraes de O.; LOPES, Maria Margaret. Para ler Bertha Lutz. Cadernos Pagu, Campinas, n. 24, p. 315-325, 2005. 